Bond University

Research Repository

\title{
Effects of a 12-Week Cycling Intervention on Successful Aging Measures in Mid-Aged Adults
}

Geard, David; Rebar, Amanda L; Dionigi, Rylee A; Rathbone, Evelyne; Reaburn, Peter

Published in:

Research Quarterly for Exercise and Sport

DOI:

10.1080/02701367.2020.1724861

Licence:

Other

Link to output in Bond University research repository.

Recommended citation(APA):

Geard, D., Rebar, A. L., Dionigi, R. A., Rathbone, E., \& Reaburn, P. (2021). Effects of a 12-Week Cycling Intervention on Successful Aging Measures in Mid-Aged Adults. Research Quarterly for Exercise and Sport, 92(1), 170-181. https://doi.org/10.1080/02701367.2020.1724861

\section{General rights}

Copyright and moral rights for the publications made accessible in the public portal are retained by the authors and/or other copyright owners and it is a condition of accessing publications that users recognise and abide by the legal requirements associated with these rights.

For more information, or if you believe that this document breaches copyright, please contact the Bond University research repository coordinator. 


\title{
SUCCESSFUL AGING AND CYCLING
}

Effects of a 12-week cycling intervention on successful aging measures in mid-aged adults

David Geard, Amanda L. Rebar, Rylee A. Dionigi, Evelyne Rathbone, and Peter Reaburn

\begin{abstract}
Author Note
David Geard, Amanda L. Rebar, and Peter Reaburn, School of Health, Medical and Applied Sciences, Central Queensland University, Rockhampton, Australia; Rylee A. Dionigi, School of Exercise Science, Sport and Health, Charles Sturt University, Port Macquarie, Australia; Evelyne Rathbone, Faculty of Health Sciences \& Medicine, Bond University, Gold Coast, Australia.
\end{abstract}

Peter Reaburn is now at the Faculty of Health Sciences \& Medicine, Bond University, Gold Coast, Australia.

This research received no specific grant from any funding agency in the public, commercial, or not-for-profit sectors. The study was pre-approved by the local Institutional Review Board pre-approved (H15/03-051), and prospectively registered with the Australian New Zealand Clinical Trial Registry (ACTRN12615000420549). The Authors declare that there is no conflict of interest. All data and information pertaining to this manuscript can be accessed by contacting the corresponding author. The Authors wish to thank Greg Rowsell for his assistance with elements of the study design.

Correspondence concerning this article should be addressed to David Geard, School of Health, Medical and Applied Sciences, Central Queensland University, Australia. Phone: +61 7 409340 35. Email: dgeard@ cqu.edu.au

Keywords: competition, functioning, physical activity, training 


\section{SUCCESSFUL AGING AND CYCLING}

4 Purpose: To compare the effect of 12-weeks of cycling training and competition versus recreational cycling on successful aging across physical, psychological, cognitive, and social functioning domains in mid-aged adults. Methods: Recreational cyclists were randomly assigned to an intervention $(n=13, \mathrm{M}$ age $=47.18$ years $)$ and comparison $(n=13, \mathrm{M}$ age $=$ 46.91 years) group. Analysis of Covariance was used on self-reported pre-post data to determine changes across time and differences between groups on outcomes. Results: The intervention group scored higher on the role limitation due to physical problems measure of physical functioning $(p=.045)$ and the social activity measure of social functioning ( $p$ $=.008)$ with large effect sizes $\left(\eta_{p}^{2}>.14\right)$. The remaining physical, psychological, cognitive, and social functioning measures were not significantly different $(p>.05)$ between groups with small to medium effect sizes $\left(\eta_{p}{ }^{2}>.01\right.$ to $\left.\leq .06\right)$. Conclusion: Cycling training and competition promotes better physical and social functioning than recreational cycling. This finding indicates that an intervention that incorporates the training and competition aspects of sport may promote positive outcomes that are above and beyond those that can be gained from participation in recreational physical activity. Objective measurements on larger samples across a broader range of sports are required to confirm and extend these findings. Keywords: competition, functioning, physical activity, training

\section{Abstract}




\section{SUCCESSFUL AGING AND CYCLING}

The world's population is currently aging chronologically and biologically for longer than any other time in human history (United Nations, 2017). The extension of chronological aging (years since birth) has raised the global life expectancy of men and women combined to an unprecedented 71 years (United Nations, 2017). However, the extension of biological aging, the molecular and cellular structural and functional degenerative changes that occur over time, increases people's risk of morbidity (Hayflick, 1998). Longer lives coupled with age-associated morbidity is projected to strain societal healthcare, welfare, and financial systems across the globe (United Nations, 2017). Thus, it is incumbent upon gerontologists to identify strategies that will promote "successful aging" for as long as possible before the end of life.

Gerontologists have been interested in the concept of successful aging for over six decades (Havighurst, 1961; Pruchno, 2018; Rowe \& Kahn, 1987). However, as the health, welfare, and financial challenges associated with global population aging have become more apparent (Bloom, Canning, \& Lubet, 2015), aging researchers have increasingly prioritized successful aging research (Wahl, Deeg, \& Litwin, 2016). Consequently, large-scale research collaborations have been conducted (Rowe \& Kahn, 1997), and special editions of prestigious academic journals have been published (Pruchno, 2015) with the aim of discussing and promoting successful aging. Despite the increasing focus on and long history of successful aging research, scholars are divided on whether successful aging is a useful concept to investigate.

The majority of critiques of the successful aging concept argue that successful aging research discriminates against and excludes that proportion of the adult population who are at the less advantaged end of the social, health, or wealth spectrum because their location on this spectrum renders them less able or unable to engage with successful aging promotional strategies (Martinson \& Berridge, 2015). Despite this criticism, because of the large body of 
SUCCESSFUL AGING AND CYCLING

ongoing research and accumulated knowledge, scholars generally agree that improving how the successful aging concept is used is preferable to abandoning it (Bowling \& Dieppe, 2005; Pruchno, 2015).

In addition to the lack of consensus regarding the merits of successful aging research, researchers do not agree on how to define or model successful aging. Historically, scholars have conceptualized successful aging in a manner that reflects their own academic or professional discipline (Bowling, 2007). For example, the most popular psychosocial model suggests that people can age successfully if they psychologically adapt to the physical, cognitive, and social losses they endure as they get chronologically older (Baltes \& Carstensen, 1996). Alternatively, the most widely adopted biomedical-oriented model suggests that people can age successfully if they avoid disease, remain engaged with life, and maintain high physical and cognitive function (Rowe \& Kahn, 1997).

The lack of consensus regarding how to define successful aging has resulted in the development of a high number of different operational definitions and models (Cosco, Prina, Perales, Stephan, \& Brayne, 2014). However, across studies the systematic review findings indicate that successful aging is broadly conceptualized as a desired, positive, health-related phenomenon that adults experience as they age chronologically, which encompasses high functioning across physical, psychological, cognitive, and social domains (Bowling, 2007; Cosco et al., 2014; Depp \& Jeste, 2006). Therefore, in line with previous research (Kok, Aartsen, Deeg, \& Huisman, 2017; von Faber et al., 2001), for the purposes of the present study, successful aging is operationally defined as high physical, psychological, cognitive, and social functioning.

Cross-sectional research findings indicate that people who engage in a higher level of physical activity — any bodily movement produced by skeletal muscle that results in energy expenditure (Caspersen, Powell, \& Christenson, 1985) — are more than twice as likely to age 


\section{SUCCESSFUL AGING AND CYCLING}

successfully across the physical, mental, and social domains compared to age-matched less physically active people (Baker, Meisner, Logan, Kungl, \& Weir, 2009). Moreover, longitudinal research findings indicate that a higher level of physical activity significantly and independently predicts multidimensional successful aging in mid-aged and older adults (Gopinath, Kifley, Flood, \& Mitchell, 2018; Peel, McClure, \& Bartlett, 2005).

Masters athletes systematically train for and compete in sporting events that are specifically designed for adults who are mid-aged and older (Dionigi, 2016; Reaburn \& Dascombe, 2008). The physical activity that Masters athletes engage in through their sports participation enable them to continue participating in their chosen sport well into later life (Ransdell, Vener, \& Huberty, 2009) when many age-matched non-athletes are losing their physical functional independence (Shephard, 2009). Consequently, Masters athletes are often referred to as the physical elite of their respective age cohorts (Baker, Fraser-Thomas, Dionigi, \& Horton, 2010) and models of successful physical aging (Hawkins, Wiswell, \& Marcell, 2003; Tanaka \& Seals, 2008).

In addition to the obvious physical functioning benefits, the physical activity that Masters athletes engage in has shown to be associated with psychological, cognitive, and social functioning benefits such as less depression, distress, and stress; better reaction time, attention, coordination, and accuracy during daily tasks; and a higher level of perceived and actual social interaction, respectively (Eime, Young, Harvey, Charity, \& Payne, 2013; Leach \& Ruckert, 2016). The physical activity Masters athletes engage in has thus recently been suggested to promote successful aging across the physical, psychological, cognitive, and social functioning domains (Geard, Reaburn, Rebar, \& Dionigi, 2017).

The above research findings show that the physical activity that is inherent to sports participation is linked to multidimensional successful aging. However, beyond being physically active, sport also requires participants to train for and compete in their chosen 
SUCCESSFUL AGING AND CYCLING

96

sport, adhere to sport-specific rules, apply sport-specific skills, and interact with others.

Scholars have hypothesized that sport-specific factors such as these can promote successful multidimensional aging above that which is achieved through physical activity alone (Baker et al., 2010; Geard, Rebar, Reaburn, \& Dionigi, 2018). However, to date, this question has not been experimentally studied to date.

Training and competition are chief among the factors that distinguish sport from physical activity. Therefore, we implemented a cycling training and competition intervention to determine if these unique aspects of sport promote successful aging across the physical, psychological, cognitive, and social functioning domains more than recreational cycling. We hypothesized that the participants who performed the cycling training and competition intervention would demonstrate higher functioning than the recreational cycling participants across all domains.

\section{Methods}

We conducted a 12-week, two-arm, pre-post, randomized controlled cycling trial in Rockhampton, Australia from July 13 to September 27, 2015. The study was approved by the Human Research Ethics Committee from the principal researcher's institution (H15/03-051), and prospectively registered with the Australian New Zealand Clinical Trial Registry (ACTRN12615000420549). Neither the principal researcher nor research participants were blinded to the allocation of intervention conditions.

\section{Participant Recruitment}

Cycling is among the most popular sports in the regional location where the present study was conducted. Therefore, we selected cycling as the present study's intervention to maximize participant recruitment. An informational flyer was posted to the websites of local recreational cycling organizations, which encouraged people to attend a pre-study information session if they: (a) were aged 40 years or older; (b) were current recreational 


\section{SUCCESSFUL AGING AND CYCLING}

cyclists — defined as being involved in cycling as an individual or member of a group, but not involved in systematic training or regular competition for at least the last 10 years; and (c) did not have musculoskeletal, cardiovascular, or metabolic risk factors and conditions, or any other medical problem that would make it dangerous to participate in high intensity physical activity. Attendees at the information session were provided with all details of the study including start and finish dates, pre- and post-intervention testing activities, training and competition requirements. Those who volunteered to participate were asked to provide informed consent, confirm their availability to attend all study-related activities, and leave their telephone number so they could be contacted to arrange a face-to-face pre-participation medical screening.

\section{Medical Screening and Random Assignment}

An Exercise and Sports Science Australia (ESSA)-accredited exercise physiologist interviewed potential study participants using the ESSA Adult Pre-Exercise Screening System (2012). Age, sex, height, body mass, resting blood pressure, smoking, symptoms and family history of major non-communicable diseases, injury status, frequency and duration of weekly exercise data were collected to: (a) identify disease, or signs or symptoms of disease that may increase the risk of an adverse event during physical activity/exercise; (b) stratify risk profile; and (c) inform the prescription of safe training programs for those individuals who were assigned to the intervention arm of the study. Individuals who were stratified higher than "low risk" but still wanted to participate in the study were referred to their treating general practitioner for final medical clearance. After being medically cleared, 26 recreational cyclists were randomly assigned to an intervention group (IG, $n=13$ ) or comparison group (CG, $n=13)$. The flow of participants through this trial is shown in Figure 1. 
SUCCESSFUL AGING AND CYCLING

\section{Data Collection and Measures}

A web-based survey was used to collect sociodemographic, physical activity, and physical, psychological, cognitive, and social functioning data. Participants' maximum oxygen uptake $\left(\mathrm{VO}_{2 \max }\right)$ was determined directly in a laboratory on a cycle ergometer with a graded exercise test (GXT). All data were collected pre-intervention during the two weeks prior to the commencement of the study, and post-intervention during the week following the completion of the study.

Sociodemographic variables. Participants self-reported age (years), sex (male/female), height ( $m$ ), body mass $(\mathrm{kg})$, ethnicity (Indigenous Australian, European Australian, other), education (tertiary, high school/equivalent, none, other), and income (> \$100 000, $\$ 50000$ to $\$ 100000,<\$ 50000)$.

Physical, psychological, cognitive, and social functioning. The Veterans RAND 12Item Health Survey (VR-12) was used to measure physical and psychological functioning. The VR-12 is valid, reliable, and was developed from the Veterans RAND 36-Item Health Survey (VR-36) which was developed from the MOS RAND SF-36 Version 1.0 (Iqbal et al., 2007). Cognitive functioning was assessed with the Revised 6-Item Medical Outcomes Study Cognitive Functioning Scale (MOS Cog-R), a valid and reliable measure of cognitive functioning in adults (Yarlas, White, \& Bjorner, 2013). The social activity aspect of social functioning was also assessed with the VR-12. Other aspects of social functioning were measured with the Three-Item Loneliness Scale which is a valid, reliable, and internally consistent instrument comprised of the highest factor loaded questions from the Revised UCLA Loneliness Scale (Hughes, Waite, Hawkley, \& Cacioppo, 2004), and a novel Friends question. All Likert survey items were either a 3-point, 5-point, or 6-point scale, and linearly transformed to range from 0 to 100 . The numerical values of the survey item response options were transformed so that minimum and maximum values were consistent across survey 
SUCCESSFUL AGING AND CYCLING

171 items, higher scores represented more positive functioning, and items with different numbers of response categories could be combined into a single score (Hays, Sherbourne, \& Mazel, 1995).

Physical functioning was assessed with a composite score (i.e., raw scores were summed and averaged) of the two VR-12 physical functioning items, and a composite score of the two VR-12 role limitations due to physical problems items. Physical functioning questions asked if participants' health limited them in doing activities such as (1) moving a table, pushing a vacuum cleaner, bowling or playing golf etc., and (2) climbing several flights of stairs. The three response options were: $0=$ limited a lot, $50=$ limited a little, $100=$ not limited. Role limitations due to physical problems questions asked if participants had (1) little of the time, $100=$ none of the time. The role limitations due to emotional problems 


\section{SUCCESSFUL AGING AND CYCLING}

they would like, and (2) didn't do work or other activities as carefully as usual as a result of emotional problems such as feeling depressed or anxious. The five response options were: 0 $=$ all the time, $25=$ most of the time, $50=$ some of the time, $75=$ a little of the time, $100=$ none of the time.

Cognitive functioning was assessed with a composite score of the six MOS Cog-R questions which asked how much of the time over the past four weeks participants had (1) difficulty reasoning and solving problems, (2) difficulty doing activities involving concentration and thinking, (3) become confused and started several actions at a time, (4) forgotten things that happened recently, (5) trouble keeping their attention on any activity, (6) reacted slowly to things that were said or done. The five response options were: $0=$ all the time, $25=$ most of the time, $50=$ some of the time, $75=$ a little of the time, $100=$ none of the time.

The VR-12 social functioning item measured social activity by asking how much of the time during the past four weeks physical health or emotional problems interfered with participants social activities like visiting friends and relatives. The five response options were: $0=$ all the time, $25=$ most of the time, $50=$ some of the time, $75=$ a little of the time, $100=$ none of the time. The Three-Item Loneliness Scale items asked how often participants felt (1) lacking in companionship, (2) left out, and (3) isolated from others. The three response options were: $0=$ often, $50=$ some of the time, $100=$ hardly ever. The Friends question asked respondents how many friends (i.e., people they saw regularly, did activities with etc.) they had.

Physical activity. We assessed physical activity level with the International Physical Activity Questionnaire-Short Form (IPAQ-SF), a self-report surveillance measure that has been validated on 18-65 year old adults (Craig et al., 2003). The IPAQ-SF questions asked participants how long (i.e., hours and minutes per day) and frequently (i.e., days in the last 


\section{SUCCESSFUL AGING AND CYCLING}

seven days) they were engaged in vigorous, moderate, and walking intensity physical activity. The weekly minutes spent doing physical activity at each intensity was multiplied by the metabolic equivalent (MET) values 8.0, 4.0, and 3.3, respectively, and the resulting MET scores summed as a single continuous variable (MET-minutes/week).

$\mathbf{V O}_{2 \max }$. To determine each participant's $\mathrm{VO}_{2 \max }$, we conducted a GXT with a computer controlled and electromagnetically-braked cycle ergometer (Velotron, Dynafit Pro,

RacerMate; Seattle, WA, USA), using a calibrated indirect calorimetry system (TrueOne 2400, Parvo Medics, Inc.; Sandy, USA). Participants were instructed not to eat or smoke within the two hours prior to the GXT. The cycle ergometer seat height, room temperature, time of test, and all other conditions and procedures established at the pre-intervention test were replicated for the post-intervention test. Prior to each GXT, participants were instructed to maintain a pedaling cadence of $90 \mathrm{rpm}$. The GXT commenced after a six-minute warm up at 100 Watts (W), and the initial workload of $150 \mathrm{~W}$ was increased by $50 \mathrm{~W}$ every three minutes. The GXT was terminated and $\mathrm{VO}_{2 \max }$ determined if the participant indicated they could not continue, or if; (1) respiratory exchange ratio was $\geq 1.05$, (2) heart rate was within $\pm 5 \mathrm{bpm}$ of age predicted $\mathrm{HR}_{\max }\left(220\right.$ - age), or (3) there was a plateau in $\mathrm{VO}_{2}$ (increase of < $50 \mathrm{ml} \mathrm{O}_{2}$ ) with increasing workload (Wiswell et al., 2001). Once the test was terminated, participants continued pedaling at a self-selected cadence for a period of five minutes to reestablish near-resting physiological parameters.

\section{The Cycling Intervention}

Data collected at the pre-intervention medical screening and GXT, and the cycling events that participants indicated they would compete in, were used by an accredited cycling coach/sports scientist to prescribe a personalized and periodized cycling training program for each IG participant for the first week of the study. The IG participants were instructed to compete in a total of at least three road-cycling events, and complete three cycling training 


\section{SUCCESSFUL AGING AND CYCLING}

sessions each week of the study. The IG participants selected the cycling competitions from the local cycling club competition calendar based on their individual availability. One weekly training session was completed by all participants together under the supervision of the principal investigator using cycle ergometers at a local fitness club. The other two weekly training sessions were performed in the participants' own time.

Competitions were performed at a self-selected intensity, on average 60 minutes in duration, and endurance focused. All training sessions were 45-60 minutes in duration, and high-intensity intervals where participants cycled for 60 to 90 seconds at $85 \%$ to $90 \% \mathrm{HR}_{\max }$ followed by $2-3$ minutes of recovery cycling at $65 \%$ to $75 \% \mathrm{HR}_{\max }$. To encourage adherence to the cycling intervention, the principal investigator telephoned IG participants when they were absent from a training session or competition that they had previously indicated they would attend. Based on information provided by IG participants' responses to a number of training diary questions, the training programs were reviewed and modified at the end of each week of the study by the cycling coach/sports scientist, and emailed back to IG participants prior to the next week of the study.

The training diary consisted of questions on training session duration (mins) and intensity $(0=$ very light to $10=$ very hard $)$, sleep quality during the night after each training session $(0=$ very bad to $10=$ very good $)$, fatigue $(0=$ no fatigue at all to $10=$ maximum fatigue $)$ and muscle soreness $(0=$ none at all to $10=$ maximal soreness $)$ the day after each training session. Based on the participants' responses to these questions, training variables such as cadence, time spent at a specific $\%$ of $\mathrm{HR}_{\max }$, and time spent pedaling while seated on or off the bicycle seat during training sessions were manipulated to provide the appropriate training stimulus.

The CG participants were instructed to maintain their pre-study recreational cycling activities, refrain from participating in systematic cycling training or competition during the 


\section{SUCCESSFUL AGING AND CYCLING}

study, and were asked via a post-intervention survey question if they reduced, maintained, or increased their cycling activities compared to before the study. The CG participants were organized as a version of a waitlist to encourage participant retention, and given the opportunity to receive the same cycling training program, and attend the same number of cycling competitions during the following road cycling season, that the IG participants received and competed in respectively during the present study.

\section{Data Analysis}

Data analyses were conducted with IBM SPSS Statistics Version 24 (Chicago, Ill, USA). Due to the low sample size, we used multiple imputation (Biering, Hjollund, \& Frydenberg, 2015) based on five imputed datasets to account for values not provided by study participants $(5.9 \%)$. We aimed to determine if the cycling intervention resulted in changes across time and differences between groups on the outcomes. Proper randomization procedures were followed, and pre-intervention variables were measured before the commencement of the intervention. Therefore, we selected analysis of covariance (ANCOVA), with the grand mean (i.e., mean of means) of both groups' pre-intervention scores as the covariate, to analyze the data because this method has shown to be the most powerful and precise approach to statistically analyze data with the present study's design (Rausch, Maxwell, \& Kelley, 2003; Read, Kendall, Carper, \& Rausch, 2013; Van Breukelen, 2006). The requisite statistical assumptions of linearity, homogeneity of regression slopes, normality, homoscedasticity, outliers, and homogeneity of variance were tested to ensure that the ANCOVA analysis would generate accurate results. The difference in adjusted postintervention means was considered to be statistically significant if $p<.05$. Partial eta squared, an estimate of variance in the dependent variable after partitioning out independent variable and covariate variation, was the chosen effect size (Richardson, 2011).

\section{Results}




\section{SUCCESSFUL AGING AND CYCLING}

Participants were European Australians, aged 40-55 years, and mainly female, tertiary educated, high-income earners. With the exception of cognitive functioning, pre-intervention variables were not significantly different across groups (Table 1). The IG participants adhered closely to the training and competition components of the cycling intervention by completing an average of 33 out of 36 training sessions, and an average of 2.70 out of three races. All CG participants indicated that they maintained their pre-study cycling activity levels throughout the study period.

\section{<Insert Table 1 here>}

Table 2 shows that the IG's adjusted post-intervention mean score on the role limitations due to physical problems measure of physical functioning $\left(p=.04 \eta_{p}^{2}=.16\right)$, the social activity measure of social functioning $\left(p=.01, \eta_{p}{ }^{2}=.27\right)$, and $\mathrm{VO}_{2 \max }\left(p=.01, \eta_{p}{ }^{2}\right.$ $=.25$ ) was significantly higher than the CG. The mental health measure of psychological functioning $(p=.13)$ and friends measure of social functioning $(p=.16)$ were not significantly different between groups but the differences were in favor of the IG with medium effect sizes $\left(\eta_{p}{ }^{2}=.10\right.$ and .09 respectively). The difference between groups was not statistically significant for the physical functioning measure $\left(p=.46, \eta_{p}{ }^{2}=.02\right)$, role limitation due to emotional problems measure of psychological functioning $\left(p=.90, \eta_{p}{ }^{2}\right.$ $<.001)$, cognitive functioning $\left(p=.62, \eta_{p}{ }^{2}=.01\right)$, loneliness measure of social functioning ( $p$ $\left.=.50, \eta_{p}^{2}=.02\right)$, or physical activity $\left(p=.46, \eta_{p}^{2}=.02\right)$ with small effect sizes.

<Insert Table 2 here>

\section{Discussion}

Physically active people are more likely to age successfully (Baker et al., 2010; Gopinath et al., 2018; Peel et al., 2005). Furthermore, due to the high levels of physical activity they undertake while participating in sport, Masters athletes have been hypothesized to be exemplars of successful aging across the physical, psychological, cognitive, and social 


\section{SUCCESSFUL AGING AND CYCLING}

321 functioning domains (Geard et al., 2017). Previous literature suggests that unique characteristics of sports participation may promote successful aging above and beyond that which is derived from physical activity participation alone (Baker et al., 2009; Geard et al., 2018). Therefore, the aim of the present study was to implement a cycling intervention to determine if the training and competition components of sport promoted better functioning across the physical, psychological, cognitive, and social domains of successful aging compared to recreational physical activity. We hypothesized that the IG would have significantly higher functioning than the CG across all domains at the end of the study.

As expected, the IG had significantly higher physical functioning on the role limitations due to physical problems measure than the $\mathrm{CG}$ at post-intervention. This indicates that the intervention promotes better physical functioning above that which was derived from the physical activity engaged in by the recreational cycling group. An increase in physical activity generally promotes physiological adaptations that can lead to higher physical functioning (Manini \& Pahor, 2009). Therefore, we also expected the cycling training and competition that the IG engaged in to translate into a higher level of physical activity, and for difference did not reach statistical significance.

Small sample size limited the present study's power to detect a significant difference in physical activity between groups. Moreover, we speculate that the cycling training and competition promoted the IG's higher physical functioning via more frequent, higher intensity, or longer duration physical activity. However, we were unable to confirm this because we calculated the physical activity variable by multiplying frequency, intensity, and duration data together. Therefore, we suspect that the small sample size or method of physical activity measurement prevented us from observing that the IG engaged in greater overall, 


\section{SUCCESSFUL AGING AND CYCLING}

more frequent, higher intensity, or longer duration physical activity than the $\mathrm{CG}$, and that this was responsible for the IG's higher physical functioning.

This proposition is supported by qualitative research findings that indicate that Masters sport participants are motivated to train harder because of their desire to compete at a higher level (Dionigi, Baker, \& Horton, 2011; Shephard, Kavanagh, Mertens, Qureshi, \& Clark, 1995). Moreover, quantitative research shows that frequent high intensity cycling training promotes better performance among older adults on daily physical tasks (Bellumori, Uygur, \& Knight, 2017; Van Roie et al., 2017). Although the present study does not explicitly address the effects of training and competition on physical functional independence, given that physical functioning inherently declines over time from a peak in early adulthood (Shephard, 2009), the present study's data suggest that training and competition may delay the loss of independence that many people eventually experience in later life.

Contrary to our expectation, the cycling intervention did not promote better physical functioning than recreational cycling on the role limitations due to physical problems measure of physical functioning. However, it is noteworthy to mention that both the intervention and comparison groups were physically active through their cycling activity. Therefore, given that previous research indicates that physical activity participation is associated with successful aging (Baker et al., 2009, Gopinath et al., 2018) we suggest both groups were aging more successfully than less active age-matched people from the general population.

The available research evidence shows that cycling training interventions of similar frequency, intensity, and duration can improve performance on physical functioning tests of mobility and strength in older lower functioning adults (Van Roie et al., 2017; Varela, Ayán, Cancela, \& Martín, 2012). Moreover, all participants in the present study were mid-aged adults with $\mathrm{VO}_{2 \max }$ scores well above that associated with a loss of independence (Shephard, 


\section{SUCCESSFUL AGING AND CYCLING}

2009); the physical functioning measure we utilized asked participants if they were limited in basic and not more advanced activities of daily living, and a high proportion of participants reported maximum pre-intervention (65\%) and post-intervention (73\%) scores. We suggest that a ceiling effect may have concealed the physical functioning difference between groups. Thus, the use of a more sensitive physical functioning measure may have demonstrated that cycling training and competition can promote better physical functioning than recreational cycling.

The present study's findings suggest that the 12-week cycling training and competition intervention is no better than recreational cycling with regards to enhancing psychological and cognitive functioning. Research findings on the combined effect of cycling training and competition versus recreational cycling for psychological and cognitive functioning is in short supply. However, previous cycling training interventions of a similar frequency, intensity, time, and type to that used in the present study have shown to promote better psychological functioning in mid-aged adults on measures of affect (Shepherd et al., 2015), worry, and anxiety (Herring, Jacob, Suveg, Dishman, \& O'Connor, 2012). Moreover, stationary cycling training interventions have shown to improve global cognition, attention, memory, visual scanning, processing speed (Varela, Cancela, Seijo-Martinez, \& Ayán, 2018), and reduce cognitive decline on orientation, registration, attention/calculation, recall, and language tests in older and lower functioning adults (Varela et al., 2012).

Although the present study's findings indicate that cycling training and competition does not promote better psychocognitive functioning than recreational cycling, both study groups were engaged in physical activity which is likely to promote higher scores on the present study's outcomes of interest relative to regular inactive populations. Moreover, we measured psychological and cognitive functioning with self-reports rather than clinicianadministered or computer-based performance measures. Finally, evidence of cognitive 


\section{SUCCESSFUL AGING AND CYCLING}

decline is not typical at the age that the participants in the present study were (Leach \& Ruckert, 2016). Therefore, the measures used and the relatively young age of the study participants may have prevented the IG from demonstrating better psychocognitive functioning than the CG, and although the present study's intervention did not promote better psychocognitive functioning than recreational cycling, it is likely both groups were aging more successfully than less active populations.

The IG reported being significantly more socially active and having more social connections (non-significant, medium effect size) than the CG after the study. The IG performed their prescribed training sessions as a group. Moreover, although we did not collect this data, many IG participants indicated that they attended competitions together. To our knowledge, previous research has not compared the benefits of cycling training and competition versus recreational cycling for social outcomes. However, Masters cycling participants have reported that they primarily participate because of the social nature of their sport (Baker et al., 2010; Dionigi et al., 2011), and that their participation promotes familial as well as peer support (Appleby \& Dieffenbach, 2016). Moreover, beyond the cyclingspecific literature, qualitative research findings indicate that participants from a range of sports derive a sense of community as a result of their involvement (Lyons \& Dionigi, 2007). Therefore, given the link between physical activity and successful aging, it is likely that the social environment in which the intervention activities were set promoted greater social activity and interaction than non-active people from the broader population as well as the CG. Our findings suggest that cycling training and competition does not impact loneliness any more than recreational cycling. The effect of cycling on loneliness has not previously been examined. However, the type of social activity and support that previous research findings (Gayman, Fraser-Thomas, Dionigi, Horton, \& Baker, 2016) and the present study's results suggest are available to adult sport participants have shown to reduce loneliness across 


\section{SUCCESSFUL AGING AND CYCLING}

a number of intervention studies (Masi, Chen, Hawkley, \& Cacioppo, 2011). Participants in the intervention studies that Masi et al. (2011) reviewed were not cyclists, at times lonely at baseline, and older than those from the present study. Therefore, generalizing these earlier findings to our data should be done cautiously. The IG from the present study reported being lonelier lonely prior to the study than the CG and less lonely after the study had concluded. Moreover, the power to detect a significant difference between the present study's groups was suboptimal due to the small sample size. Although the finding was not statistically significant, we speculate that the lower loneliness that was reported after the study by the IG is a practically important finding that should be investigated through further research.

\section{Study Strengths}

With the exception of recent non-experimental investigations (Berlin, Kruger, \& Klenosky, 2018; Geard et al., 2018), research on the relationship between aspects of sport training and competition and successful aging in mid-aged and older adults has to date consisted of reviews that discuss sport in general and characterize successful aging from a physical or physiological perspective (Hawkins et al., 2003; Tanaka \& Seals, 2008). However, cycling is one example of a high number of different sports, and successful aging as it is currently conceptualized within the broader literature is a multidimensional phenomenon. Therefore, the major strength of the present study is that it is the first to focus on mid-aged and older adults participating in a specific sport using a multidimensional conceptualization of successful aging. A second strength is that the present study's randomized controlled trial design allows us to draw firm conclusions regarding causality. Third, successful aging is a complex term that has proven difficult to define. However, the present study provides an operational definition that future researchers can build upon. To the best of the authors' knowledge, the present study is the first to compare the effect of specific aspects of sports (i.e., enhanced training and competition) and physical activity on measures 


\section{SUCCESSFUL AGING AND CYCLING}

of successful aging. Therefore, a fourth strength of the study is that we report novel findings on how sport training and competition promote positive aging outcomes that are above and beyond those conferred by recreational physical activity, which we know is positively associated with successful aging. Finally, the present study encourages multidisciplinary research by discussing the gerontological concept of successful aging within a sports science context.

\section{Study Limitations and Future Research Directions}

A number of study limitations should be considered by those undertaking successful aging research in the context of sports participation. First, the regional location of the study and only posting study informational flyers to recreational cycling organization websites may have limited the number of people who expressed interest in participating in the study. Thus, the small sample size may have prevented us from reaching optimal power and effect size. Future researchers should recruit as many participants as possible to ensure findings are valid and reliable, and assign a proportion of them to an active control or comparison group that is exposed to some other health-enhancing intervention not empirically related to the outcome(s) of interest. Second, the sociodemographic data indicated that study participants were from a homogeneous population. Therefore, the present study's findings need to be tested on more heterogeneous study samples. Third, personal and lifestyle factors such as diet, intelligence, and the presence of mental health conditions may influence functioning across the domains of the present study's successful aging model. Thus, future researchers should control variables such as these in future investigations. Fourth, sports participation is a physically, cognitively, and socially engaging activity (Lee \& Payne, 2015). While we estimated physical activity level in the present study, we did not evaluate cognitive or social activity. Given that cognitive and social activity influences at least the cognitive and social functioning domains, researchers who conduct successful aging-sport investigations in the 


\section{SUCCESSFUL AGING AND CYCLING}

471 future should attempt to quantify and assess the influence of these other aspects of sport.

472 Fifth, we investigated the effects of the training and competition aspects of sport on measures 473 of successful aging. However, sport is different to recreational physical activity in a number

474 of other ways that may influence the outcomes that were of interest to the present study. For example, the adherence to sport-specific rules and the application of sport-specific skills may promote cognitive adaptation (Lobjois, Benguigui, \& Bertsch, 2006), and participation in team sports may promote psychosocial changes (Sheehy \& Hodge, 2015). Therefore, future researchers should continue looking at the benefits that sport can provide that are above and beyond those related to physical activity. Finally, we used self-report measures to evaluate objectively measurable physical activity, and physical, cognitive, and social (i.e., the social activity and friends aspects) functioning. Further, we calculated composite scores to determine if groups differed across outcome variables. However, self-report measures do not always agree with objective assessments, and the composite scores we calculated made it impossible to determine differences in sub-domain functions such as concentration versus memory within the cognitive domain, and anxiety versus depressive symptoms within the psychological domain. Therefore, future researchers should minimize the use of self-reports and composite scores if practical.

\section{Conclusion}

Research findings regularly show that people who perform more physical activity are more likely to age successfully (Baker et al., 2009; Gopinath et al., 2018). However, prior to the present study, research on the benefits that certain aspects of sports participation can promote above physical activity alone had not been undertaken. To determine if the training and competition aspects of sport participation provide additional benefits for successful aging above and beyond those conferred by physical activity we conducted a cycling intervention. 


\section{SUCCESSFUL AGING AND CYCLING}

497

498

499

500

501

502

503

504

505

506

507

508

509

and social functioning than recreational cycling in mid-aged adults. The present study

provides a research design that other researchers can model and build upon, study strengths to embrace, and study limitations to avoid. If researchers utilize the knowledge gained from this initial study, a clearer picture of the differential benefits of physical activity and sports participation for successful aging may emerge.

\section{What Does This Article Add?}

Sport represents a large variety of activities that differ with respect to the physical, cognitive, and social activity that is involved. Moreover, successful aging has been historically difficult to define. Clearly, sport and successful aging are complex terms. Therefore, this article adds to the body of knowledge on this topic an example of how the complex relationship between sport and successful aging might be studied, novel research findings that suggest certain aspects of sport offer successful aging benefits above and beyond those that physical activity offers, and future research directions than can be followed to investigate the relationship between other aspects of sport and successful aging. 
SUCCESSFUL AGING AND CYCLING

\section{References}

Adult Pre-Exercise Screening System. (2012, March). Retrieved from https://www.essa.org.au/

Appleby, K., \& Dieffenbach, K. (2016). "Older and faster": Exploring elite masters cyclists' involvement in competitive sport. The Sport Psychologist, 30(1), 13-23. doi:10.1123/tsp.2014-0110

Baker, J., Fraser-Thomas, J., Dionigi, R. A., \& Horton, S. (2010). Sport participation and positive development in older persons. European Review of Aging and Physical Activity, 7(1), 3-12. doi:10.1007/s11556-009-0054-9

Baker, J., Meisner, B. A., Logan, A. J., Kungl, A. M., \& Weir, P. (2009). Physical activity and successful aging in Canadian older adults. Journal of Aging and Physical Activity, 17(2), 223-235. doi:10.1123/japa.17.2.223

Baltes, M., \& Carstensen, L. (1996). The Process of Successful Ageing. Ageing and Society, 16(4), 397-422. doi:10.1017/S0144686X00003603

Bellumori, M., Uygur, M., \& Knight, C. A. (2017). High-speed cycling intervention improves rate-dependent mobility in older adults. Medicine \& Science in Sports \& Exercise, 49(1), 106-114. doi:10.1249/MSS.0000000000001069

Berlin, K., Kruger, T., \& Klenosky, D. B. (2018). A mixed-methods investigation of successful aging among older women engaged in sports-based versus exercise-based leisure time physical activities. Journal of Women \& Aging, 30(1), 27-37. doi:10.1080/08952841.2016.1259439

Biering, K., Hjollund, N. H., \& Frydenberg, M. (2015). Using multiple imputation to deal with missing data and attrition in longitudinal studies with repeated measures of patient-reported outcomes. Clinical Epidemiology, 7, 91-106. doi:10.2147/CLEP.S72247 


\section{SUCCESSFUL AGING AND CYCLING}

535 Bloom, D. E., Canning, D., \& Lubet, A. (2015). Global population aging: Facts, challenges, solutions \& perspectives. Daedalus, 144(2), 80-92.doi:10.1162/DAED_a_00332

537

Bowling, A. (2007). Aspirations for older age in the 21st century: What is successful aging? The International Journal of Aging and Human Development, 64(3), 263-297. doi:10.2190/L0K1-87W4-9R01-7127

Bowling, A., \& Dieppe, P. (2005). What is successful ageing and who should define it? BMJ: British Medical Journal, 331(7531), 1548-1551. doi:10.1136/bmj.331.7531.1548

Caspersen, C. J., Powell, K. E., \& Christenson, G. M. (1985). Physical activity, exercise, and physical fitness: definitions and distinctions for health-related research. Public Health Reports, 100(2), 126-131.

Cosco, T. D., Prina, A. M., Perales, J., Stephan, B. C., \& Brayne, C. (2014). Operational definitions of successful aging: A systematic review. International Psychogeriatrics, 26(3), 373-381. doi:10.1017/S1041610213002287

Craig, C. L., Marshall, A. L., Sjostrom, M., Bauman, A. E., Booth, M. L., Ainsworth, B. E. . . Oja, P. (2003). International physical activity questionnaire: 12-country reliability and validity. Medicine \& Science in Sports \& Exercise, 35(8), 1381-1395. doi:10.1249/01.MSS.0000078924.61453.FB

Depp, C. A., \& Jeste, D. V. (2006). Definitions and predictors of successful aging: A comprehensive review of larger quantitative studies. The American Journal of Geriatric Psychiatry, 14(1), 6-20. doi:10.1097/01.JGP.0000192501.03069.bc

Dionigi, R. A. (2016). The Competitive Older Athlete: A Review of Psychosocial and Sociological Issues. Topics in Geriatric Rehabilitation, 32(1), 55-62. doi:10.1097/TGR.0000000000000091

Dionigi, R., Baker, J., \& Horton, S. (2011). Older Athletes' Perceived Benefits of Competition. The International Journal of Sport and Society, 2(2), 17-28. Retrieved 


\section{SUCCESSFUL AGING AND CYCLING}

from http://ijrar.cgpublisher.com/

Eime, R. M., Young, J. A., Harvey, J. T., Charity, M. J., \& Payne, W. R. (2013). A systematic review of the psychological and social benefits of participation in sport for adults: informing development of a conceptual model of health through sport. International Journal of Behavioral Nutrition and Physical Activity, 10(1), 135. doi: $10.1186 / 1479-5868-10-135$

Gayman, A. M., Fraser-Thomas, J., Dionigi, R. A., Horton, S., \& Baker, J. (2016). Is sport good for older adults? A systematic review of psychosocial outcomes of older adults' sport participation. International Review of Sport and Exercise Psychology, 10(1), 164185. doi:10.1080/1750984X.2016.1199046

Geard, D., Reaburn, P. R. J., Rebar, A. L., \& Dionigi, R. A. (2017). Masters athletes: Exemplars of successful aging? Journal of Aging and Physical Activity, 25(3), 490-500. doi:10.1123/japa.2016-0050

Geard, D., Rebar, A. L., Reaburn, P., \& Dionigi, R. (2018). Testing a model of successful aging in a cohort of masters swimmers. Journal of Aging and Physical Activity 26(2), 183-193. doi:10.1123/japa.2016-0357

Gopinath, B., Kifley, A., Flood, V. M., \& Mitchell, P. (2018). Physical activity as a determinant of successful aging over ten years. Scientific Reports, 8(1), 10522. doi:10.1038/s41598-018-28526-3

Hawkins, S. A., Wiswell, R. A., \& Marcell, T. J. (2003). Exercise and the master athlete-a model of successful aging? Journals of Gerontology. Series A: Biological Sciences and Medical Sciences, 58(11), 1009-1011. doi:10.1093/gerona/58.11.M1009

Hayflick, L. (1998). How and why we age. Experimental Gerontology, 33(7), 639-653. doi:10.1016/S0531-5565(98)00023-0

Hays, R. D., Sherbourne, C. D., \& Mazel, R. M. (1995). User's manual for the Medical 
SUCCESSFUL AGING AND CYCLING Outcomes Study (MOS) core measures of health-related quality of life. RAND Corporation, Santa Monica, CA. Retrieved from https://www.rand.org/

Havighurst, R. J. (1961). Successful Aging. The Gerontologist, 1(1), 8-13. doi:10.1093/geront/1.1.8

Herring, M. P., Jacob, M. L., Suveg, C., Dishman, R. K., \& O'Connor, P. J. (2012). Feasibility of exercise training for the short-term treatment of generalized anxiety disorder: A randomized controlled trial. Psychotherapy and Psychosomatics, 81(1), 2128. doi:10.1159/000327898

Hughes, M. E., Waite, L. J., Hawkley, L. C., \& Cacioppo, J. T. (2004). A short scale for measuring loneliness in large surveys: Results from two population-based studies. Research on Aging, 26(6), 655-672. doi:10.1177/0164027504268574

Iqbal, S. U., Rogers, W., Selim, A., Qian, S., Lee, A., Ren, X., . . Kazis, L. (2007). The Veterans RAND 12 item Health Survey (VR-12): What it is and how it is used. Retrieved from https://www.bu.edu/sph/files/2015/01/veterans_rand_12_item_health_survey_vr12_2007.pdf

Kok, A. A. L., Aartsen, M. J., Deeg, D. J. H., \& Huisman, M. (2017). Capturing the diversity of successful aging: An operational definition based on 16-year trajectories of functioning. The Gerontologist, 57(2), 240-251. doi:10.1093/geront/gnv127

Leach, S. J., \& Ruckert, E. A. (2016). Neurologic changes with aging, physical activity, and sport participation. Topics in Geriatric Rehabilitation, 32(1), 24-33. doi:10.1097/tgr.0000000000000088

Lee, C., \& Payne, L. L. (2015). Exploring the relationship between different types of serious leisure and successful aging. Activities, Adaptation \& Aging, 39(1), 1-18. doi:10.1080/01924788.2015.994415 


\section{SUCCESSFUL AGING AND CYCLING}

610 Lobjois, R., Benguigui, N., \& Bertsch, J. (2006). The effect of aging and tennis playing on coincidence-timing accuracy. Journal of Aging and Physical Activity, 14(1), 74-97. Retrieved from http://journals.humankinetics.com/journal/japa

Lyons, K., \& Dionigi, R. (2007). Transcending Emotional Community: A Qualitative Examination of Older Adults and Masters' Sports Participation. Leisure Sciences, 29(4), 375-389. doi:10.1080/01490400701394881

Manini, T. M., \& Pahor, M. (2009). Physical activity and maintaining physical function in older adults. British Journal of Sports Medicine, 43(1), 28-31. doi:10.1136/bjsm.2008.053736

Martinson, M., \& Berridge, C. (2015). Successful aging and its discontents: a systematic review of the social gerontology literature. Gerontologist, 55(1), 58-69. doi:10.1093/geront/gnu037

Masi, C. M., Chen, H. Y., Hawkley, L. C., \& Cacioppo, J. T. (2011). A meta-analysis of interventions to reduce loneliness. Personality and Social Psychology Review, 15(3), 219-266. doi:10.1177/1088868310377394

Peel, N. M., McClure, R. J., \& Bartlett, H. P. (2005). Behavioral determinants of healthy aging. American Journal of Preventive Medicine, 28(3), 298-304. doi:10.1016/j.amepre.2004.12.002

Pruchno, R. (2015). Successful Aging: Contentious Past, Productive Future. The Gerontologist, 55(1), 1-4. doi:10.1093/geront/gnv002

Pruchno, R. (2018). We know more about Successful Aging than we're telling. The Gerontologist, 58(6), 1195-1196. doi: 10.1093/geront/gny111

Ransdell, L. B., Vener, J., \& Huberty, J. (2009). Masters athletes: An analysis of running, swimming and cycling performance by age and gender. Journal of Exercise Science \& Fitness, 7(2), S61-S73. doi:10.1016/s1728-869x(09)60024-1 
SUCCESSFUL AGING AND CYCLING

Rausch, J. R., Maxwell, S. E., \& Kelley, K. (2003). Analytic Methods for Questions Pertaining to a Randomized Pretest, Posttest, Follow-Up Design. Journal of Clinical Child and Adolescent Psychology, 32(3), 467-486. doi:10.1207/S15374424JCCP3203_15

Reaburn, P., \& Dascombe, B. (2008). Endurance performance in masters athletes. European Review of Aging and Physical Activity, 5(1), 31-42. doi:10.1007/s11556-008-0029-2

Read, K. L., Kendall, P. C., Carper, M. M., \& Rausch, J. R. (2013). Statistical methods for use in the analysis of randomized clinical trials utilizing a pretreatment, posttreatment, follow-up (PPF) paradigm. In J. Comer \& P. C. Kendall (Eds.), The Oxford handbook of research strategies for clinical psychology (pp. 253-260): Oxford University Press.

Richardson, J. T. E. (2011). Eta squared and partial eta squared as measures of effect size in educational research. Educational Research Review, 6(2), 135-147. doi:10.1016/j.edurev.2010.12.001

Rowe, J. W., \& Kahn, R. L. (1987). Human aging: usual and successful. Science, 237(4811), 143-149. doi:10.1126/science.3299702

Rowe, J. W., \& Kahn, R. L. (1997). Successful aging. The Gerontologist, 37(4), 433-440. doi:10.1093/geront/37.4.433

Sheehy, T., \& Hodge, K. (2015). Motivation and morality in masters athletes: a selfdetermination theory perspective. International Journal of Sport and Exercise Psychology, 13(3), 273-285. doi:10.1080/1612197X.2014.956326

Shephard, R. J. (2009). Maximal oxygen intake and independence in old age. British Journal of Sports Medicine, 43(5), 342-346. doi:10.1136/bjsm.2007.044800

Shephard, R. J., Kavanagh, T., Mertens, D. J., Qureshi, S., \& Clark, M. (1995). Personal health benefits of Masters athletics competition. British Journal of Sports Medicine, 29(1), 35-40. doi:10.1136/bjsm.29.1.35 


\section{SUCCESSFUL AGING AND CYCLING}

Shepherd, S. O., Wilson, O. J., Taylor, A. S., Thogersen-Ntoumani, C., Adlan, A. M., Wagenmakers, A. J., \& Shaw, C. S. (2015). Low-volume high-intensity interval training in a gym setting improves cardio-metabolic and psychological health. PLOS One, 10(9), e0139056. doi:10.1371/journal.pone.0139056

Tanaka, H., \& Seals, D. R. (2008). Endurance exercise performance in masters athletes: Ageassociated changes and underlying physiological mechanisms. Journal of Physiology, 586(1), 55-63. doi:10.1113/jphysiol.2007.141879

United Nations, Department of Economic and Social Affairs, Population Division (2017). World Population Prospects: The 2017 Revision, Key Findings and Advance Tables. Working Paper No. ESA/P/WP/248. Retrieved from https://esa.un.org/unpd/wpp/publications/Files/WPP2017_KeyFindings.pdf

Van Breukelen, G. J. P. (2006). ANCOVA versus change from baseline had more power in randomized studies and more bias in nonrandomized studies. Journal of Clinical Epidemiology, 59(9), 920. doi:10.1016/j.jclinepi.2006.02.007

Varela, S., Ayán, C., Cancela, J. M., \& Martín, V. (2012). Effects of two different intensities of aerobic exercise on elderly people with mild cognitive impairment: A randomized pilot study. Clinical Rehabilitation, 26(5), 442-450. doi:10.1177/0269215511425835

Varela, S., Cancela, J. M., Seijo-Martinez, M., \& Ayan, C. (2018). Self-paced cycling improves cognition on institutionalized older adults without known cognitive impairment: A 15-month randomized controlled trial. Journal of Aging and Physical Activity, 1-29. doi:10.1123/japa.2017-0135

Van Roie, E., Martien, S., Hurkmans, E., Pelssers, J., Seghers, J., Boen, F., \& Delecluse, C. (2017). Ergometer-cycling with strict versus minimal contact supervision among the oldest adults: A cluster-randomised controlled trial. Archives of Gerontology and Geriatrics, 70, 112-122. doi:http://dx.doi.org/10.1016/j.archger.2017.01.010 


\section{SUCCESSFUL AGING AND CYCLING}

685

686

687

688

689

690

691

692

693

694

695

696

697

698

699

von Faber, M., Bootsma-van der Wiel, A., van Exel, E., Gussekloo, J., Lagaay, A., van Dongen, E., . . Westendorp, R. (2001). Successful Aging in the Oldest Old: Who Can be Characterized as Successfully Aged? Archives of Internal Medicine, 161(22), 26942700. doi:10.1001/archinte.161.22.2694

Wahl, H. W., Deeg, D., \& Litwin, H. (2016). Successful ageing as a persistent priority in ageing research. European journal of ageing, 13(1), 1-3. doi:10.1007/s10433-0160364-5

Wiswell, R. A., Hawkins, S. A., Jaque, S. V., Hyslop, D., Constantino, N., Tarpenning, K., . . S Schroeder, E. T. (2001). Relationship between physiological loss, performance decrement, and age in master athletes. The Journals of Gerontology Series A: Biological Sciences and Medical Sciences, 56(10), M618-M626. doi:10.1093/gerona/56.10.M618

Yarlas, A., White, M. K., \& Bjorner, J. B. (2013). The development and validation of a revised version of the medical outcomes study cognitive functioning scale (MOS-Cog R). Value in Health, 16(3), A34. doi:10.1016/j.jval.2013.03. 


\section{SUCCESSFUL AGING AND CYCLING}

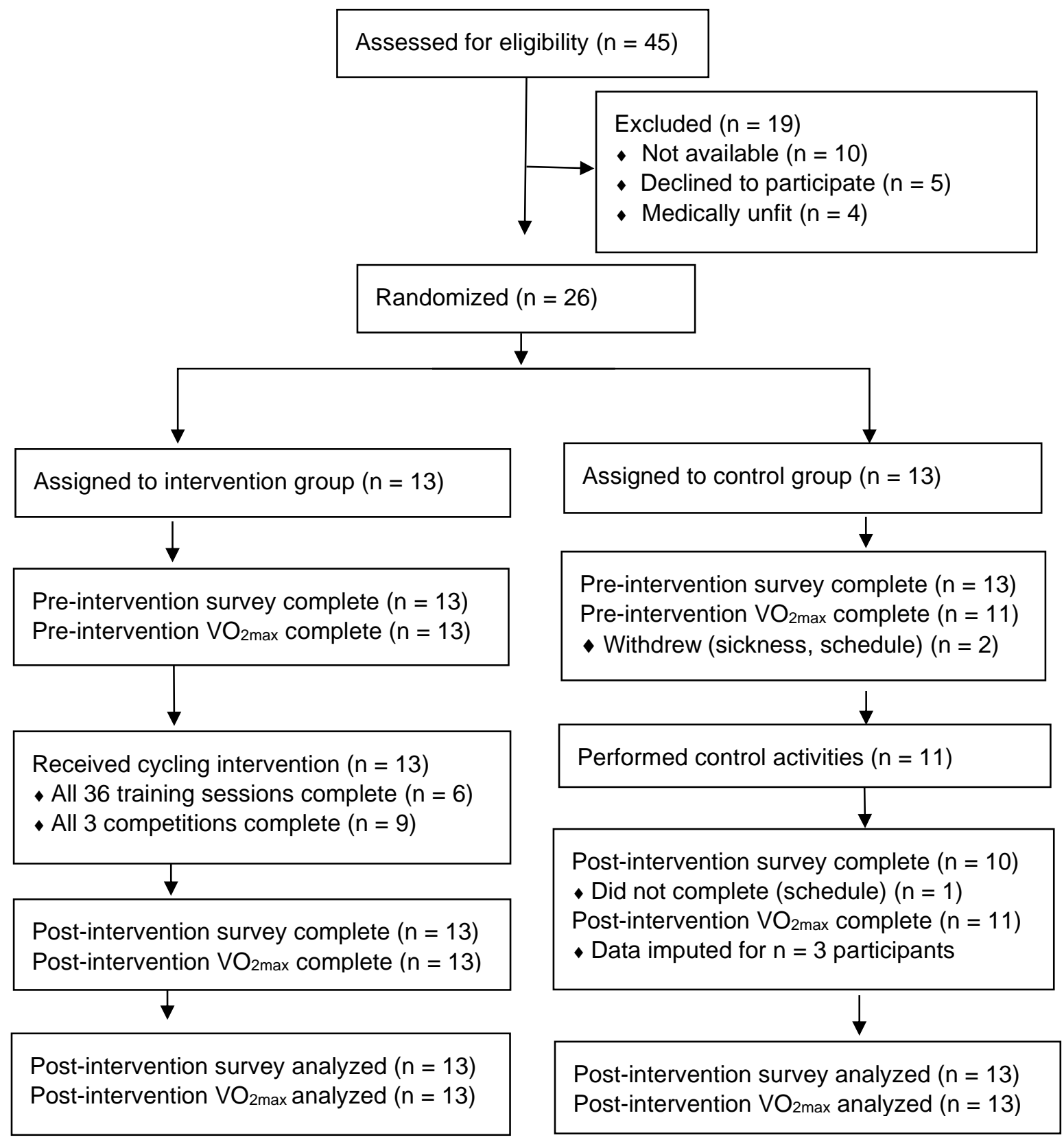

Figure 1. Flow of participants through the trial 


\section{SUCCESSFUL AGING AND CYCLING}

Table 1. Pre-intervention characteristics of participants.

\begin{tabular}{|c|c|c|c|}
\hline Variable & $\begin{array}{c}\text { Comparison Group } \\
(n=13)\end{array}$ & $\begin{array}{c}\text { Intervention Group } \\
(n=13)\end{array}$ & $p$ \\
\hline Age (years) & $46.91 \pm 4.04$ & $47.18 \pm 4.61$ & .71 \\
\hline Age (range years) & 42 to 54 & 40 to 55 & \\
\hline Sex (female) $n(\%)$ & $9(69.23)$ & $11(84.58)$ & .65 \\
\hline Height $(\mathrm{m})$ & $1.74 \pm 0.12$ & $1.68 \pm 0.12$ & .15 \\
\hline Weight (kg) & $80.67 \pm 12.70$ & $71.28 \pm 8.04$ & .07 \\
\hline \multicolumn{4}{|l|}{ Ethnicity $n(\%)$} \\
\hline European Australian & $13(100)$ & $13(100)$ & \\
\hline Education - highest completed $n(\%)$ & & & .35 \\
\hline Tertiary & $11(84.56)$ & $9(69.24)$ & \\
\hline High school/equivalent & $2(15.44)$ & $4(30.78)$ & \\
\hline Income $n(\%)$ & & & .45 \\
\hline$>\$ 100000$ & $6(45.15)$ & $8(62.04)$ & \\
\hline$\$ 50000$ to $\$ 100000$ & $5(39.01)$ & $4(30.81)$ & \\
\hline$<\$ 50000$ & $2(15.44)$ & $1(7.74)$ & \\
\hline \multicolumn{4}{|l|}{ Physical Functioning } \\
\hline Physical functioning & $90.35 \pm 12.67$ & $90.43 \pm 16.34$ & $>.99$ \\
\hline Role limitation physical problems & $87.45 \pm 13.51$ & $92.33 \pm 10.89$ & .32 \\
\hline \multicolumn{4}{|l|}{ Psychological Functioning } \\
\hline Mental health & $71.45 \pm 13.45$ & $67.73 \pm 17.89$ & .22 \\
\hline Role limitation emotional problems & $84.61 \pm 16.29$ & $77.45 \pm 15.61$ & .32 \\
\hline Cognitive Functioning & $85.32 \pm 13.02$ & $72.09 \pm 16.35$ & $.02 *$ \\
\hline \multicolumn{4}{|l|}{ Social Functioning } \\
\hline Social activity & $84.63 \pm 19.20$ & $82.67 \pm 21.43$ & .81 \\
\hline Loneliness & $74.43 \pm 20.01$ & $68.01 \pm 22.03$ & .44 \\
\hline Friends & $7.67 \pm 5.60$ & $6.44 \pm 3.21$ & .47 \\
\hline Physical activity (MET-minutes/week) & $3019.56 \pm 2803.50$ & $2803.45 \pm 1335.12$ & .99 \\
\hline $\mathrm{VO}_{2 \max }(\mathrm{ml} / \mathrm{kg} / \mathrm{min})$ & $43.44 \pm 7.21$ & $40.65 \pm 6.71$ & .30 \\
\hline
\end{tabular}

Note. Data are presented as mean $\pm \mathrm{SD}$, unless otherwise indicated. *Statistically significant difference, $p<.05$. 


\section{SUCCESSFUL AGING AND CYCLING}

Table 2. Adjusted post-intervention means and results of equality of means tests by analysis of covariance.

\begin{tabular}{|c|c|c|c|c|c|c|c|}
\hline \multirow[b]{2}{*}{ Outcome } & \multicolumn{2}{|c|}{ Comparison Group $(n=13)$} & \multicolumn{2}{|c|}{ Intervention Group $(n=13)$} & \multirow[b]{2}{*}{$F(1,23)$} & \multirow[b]{2}{*}{$p$} & \multirow[b]{2}{*}{$\eta_{p}^{2}$} \\
\hline & Mean & $95 \% \mathrm{CI}$ & Mean & $95 \% \mathrm{CI}$ & & & \\
\hline \multicolumn{8}{|l|}{ Physical Functioning } \\
\hline Physical functioning & 96.89 & $91.56-102.19$ & 94.15 & 88.94-99.48 & 0.56 & .46 & $.02^{\mathrm{a}}$ \\
\hline Role limitation physical problems & 79.73 & 68.04-91.36 & 96.89 & $85.22-108.60$ & 4.51 & $.045^{*}$ & $.16^{\mathrm{c}}$ \\
\hline \multicolumn{8}{|l|}{ Psychological Functioning } \\
\hline Mental health & 71.90 & $64.56-79.11$ & 79.71 & $72.44-86.87$ & 2.46 & .13 & $.10^{\mathrm{b}}$ \\
\hline Role limitation emotional problems & 85.18 & $78.47-91.88$ & 84.56 & $77.90-91.28$ & 0.02 & .90 & $<.001^{\mathrm{a}}$ \\
\hline Cognitive Functioning & 85.22 & $79.85-90.40$ & 87.04 & $81.80-92.34$ & 0.25 & .62 & $.01^{\mathrm{a}}$ \\
\hline \multicolumn{8}{|l|}{ Social Functioning } \\
\hline Social activity & 79.45 & $71.91-87.14$ & 94.65 & $87.11-102.32$ & 8.49 & $.008 *$ & $.27^{\mathrm{c}}$ \\
\hline Loneliness & 70.81 & $58.57-83.03$ & 76.56 & $64.39-88.78$ & 0.48 & .50 & $.02^{\mathrm{a}}$ \\
\hline Friends & 7.91 & $5.94-10.01$ & 10.08 & 7.89-12.02 & 2.13 & .16 & $.09^{\mathrm{b}}$ \\
\hline Physical activity (MET-minutes/week) & 3557.56 & $2696.42-4418.80$ & 3998.78 & $3137.56-4860.04$ & 0.56 & .46 & $.02^{\mathrm{a}}$ \\
\hline $\mathrm{VO}_{2 \max }(\mathrm{ml} / \mathrm{kg} / \mathrm{min})$ & 42.04 & $40.64-43.33$ & 44.45 & $43.20-45.92$ & 7.50 & $.01 *$ & $.25^{\mathrm{c}}$ \\
\hline
\end{tabular}

Note. Analysis of covariance (ANCOVA) was carried out on the post-intervention score for each outcome, using the grand mean of pre-intervention scores as the covariate to adjust for any pre-intervention differences between comparison and intervention groups. A higher mean score denotes a better post-intervention result. $F=$ ratio of adjusted variance between to within samples.

$*$ Statistically significant difference, $p<.05 . \eta_{\mathrm{p}}{ }^{2}=$ partial eta squared effect size measure: ${ }^{\mathrm{a}}=$ small effect size $(>.01),{ }^{\mathrm{b}}=$ medium effect size (>.06), ${ }^{c}=$ large effect size (> .14) (Richardson, 2011 
SUCCESSFUL AGING AND CYCLING 